\title{
Sobre a qualidade do superávit primário
}

Manoel Carlos de Castro Pires*

Desde a derrocada do regime de câmbio fixo, em janeiro de 1999, a política macroeconômica brasileira tem se apoiado no tripé câmbio flutuante, metas para a inflação e superávit primário. Destes três elementos o que, sem dúvida, suscita maior discussão é o superávit primário. Entretanto, a discussão em torno da implementação da política de superávit primário tem sido restrita aos termos quantitativos. Este viés é resultado da idéia que este deve ser realizado para tornar a dívida sustentável. Assim, o que importa é o montante economizado para cobrir as despesas do governo com a conta de juros e se este é ou não compatível com a estabilidade da dívida pública.

O debate se divide então entre os economistas que defendem que o superávit primário deve ser aprofundado para reduzir rapidamente a dívida e, então, reduzir a taxa de juros e entre os economistas que entendem que o Banco Central do Brasil é muito conservador na condução da política monetária e que isto traz custos fiscais muito elevados tornando o superávit primário inócuo.

Em toda discussão sobre superávit primário está ausente a questão da qualidade com a qual este vem sendo obtido. O superávit primário pode ser obtido com o aumento das receitas, com redução dos gastos ou uma combinação de ambos. Quais gastos cortar? Que tipo de imposto deve ser criado? Estas decisões têm impactos diferentes sobre a economia.

Este breve artigo pretende discutir esta questão. Argumenta-se que atribuir ao montante do superávit primário o peso da performance macroeconômica significa camuflar ou mesmo reduzir o debate. Deve-se observar a forma como este vem sendo obtido, pois melhorias nesta direção tornariam o superávit primário mais eficiente, mantendo a trajetória da dívida estável com melhores resultados sobre o crescimento de longo prazo.

\section{Evolução do superávit primário por esfera de governo}

O gráfico 1 apresenta a evolução do superávit primário dividindo suas parcelas em Governo Central e Banco Central, governos estaduais, governos municipais e empresas estatais. Pode-se observar que a contribuição do Governo Central e Banco Central é relativamente elevada e crescente no tempo. A contribuição dos governos estaduais e das

\footnotetext{
* Economista do Instituto de Pesquisa Econômica Aplicada (IPEA). Doutorando em Economia pela Universidade de Brasília (Unb). Endereço eletrônico: manoel.pires@ipea.gov.br
} 
empresas estatais também é elevada e crescente - apesar de menor que no Governo Central e Banco Central. Pode-se dizer que a participação dos governos municipais no alcance do superávit primário é desprezível.

Gráfico 1. Necessidades de financiamento do setor público - Déficit Primário

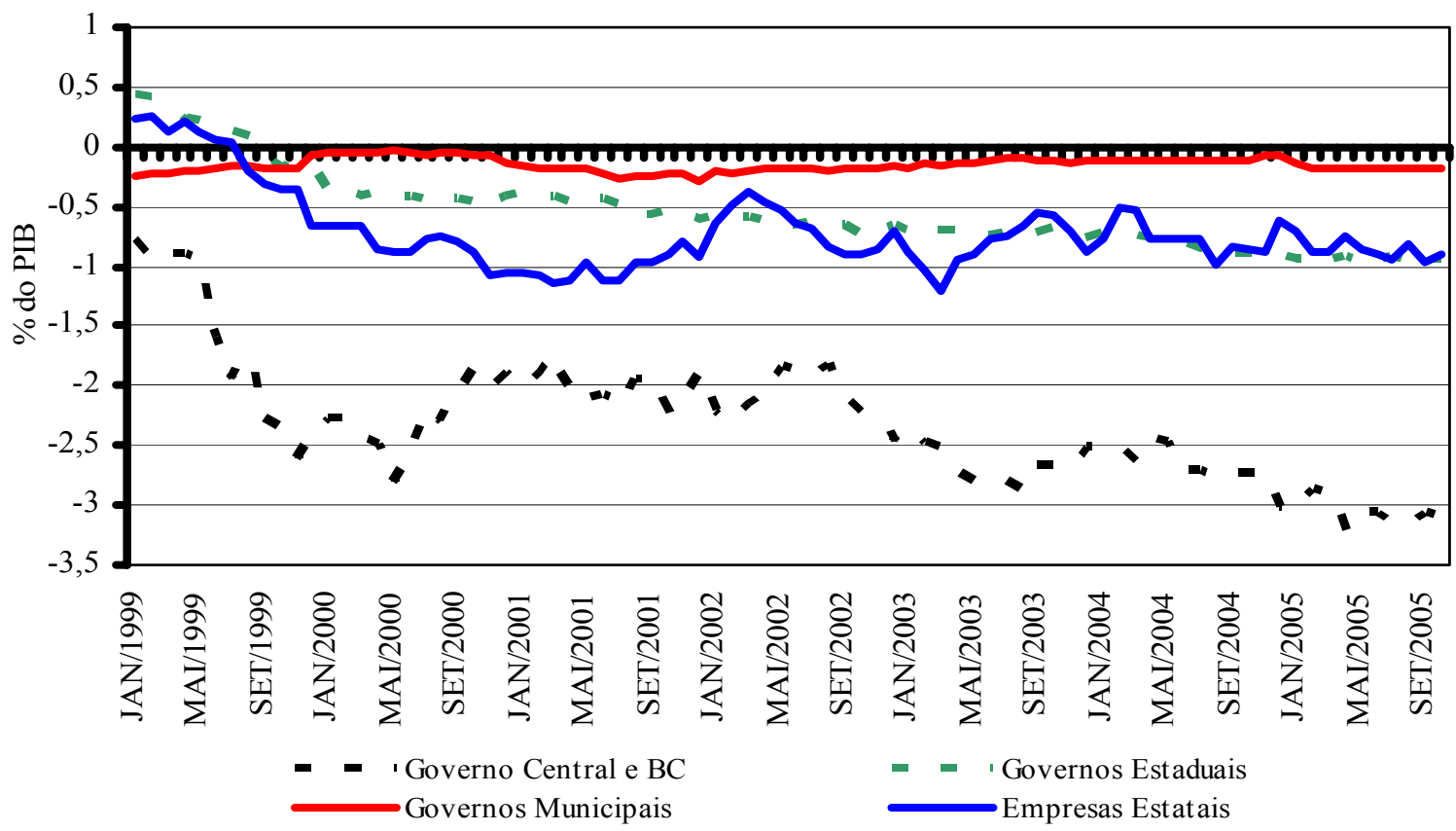

Fonte: Banco Central do Brasil

Ao analisar o gráfico acima, pode-se ter a impressão de que o Governo Central tem sofrido o maior ajuste, pois tem sido o grande responsável pela obtenção do superávit primário. Contudo, ao se observar a contribuição de cada esfera de governo em relação ao que cada uma deveria realizar para atingir o equilíbrio orçamentário, nota-se que o Governo Central tem contribuído menos do que possa parecer.

O gráfico 2 mostra a evolução do superávit primário e do pagamento de juros efetuado pelo Governo Federal e Banco Central em percentual do PIB. O montante de juros pagos pelo Governo Federal em nenhum momento foi ultrapassado pelo superávit primário obtido pelo mesmo. Em 2005, a diferença média entre o superávit primário e a despesa com juros do Governo Federal se situou próximo de 2\% do PIB. Em outras palavras, para ter coberto todo o pagamento de juros incorrido no ano, o Governo Central deveria ter obtido um superávit primário, em média, $2 \%$ do PIB mais elevado. 
Gráfico 2. Evolução do superávit primário e juros nominais - Governo Federal e BC

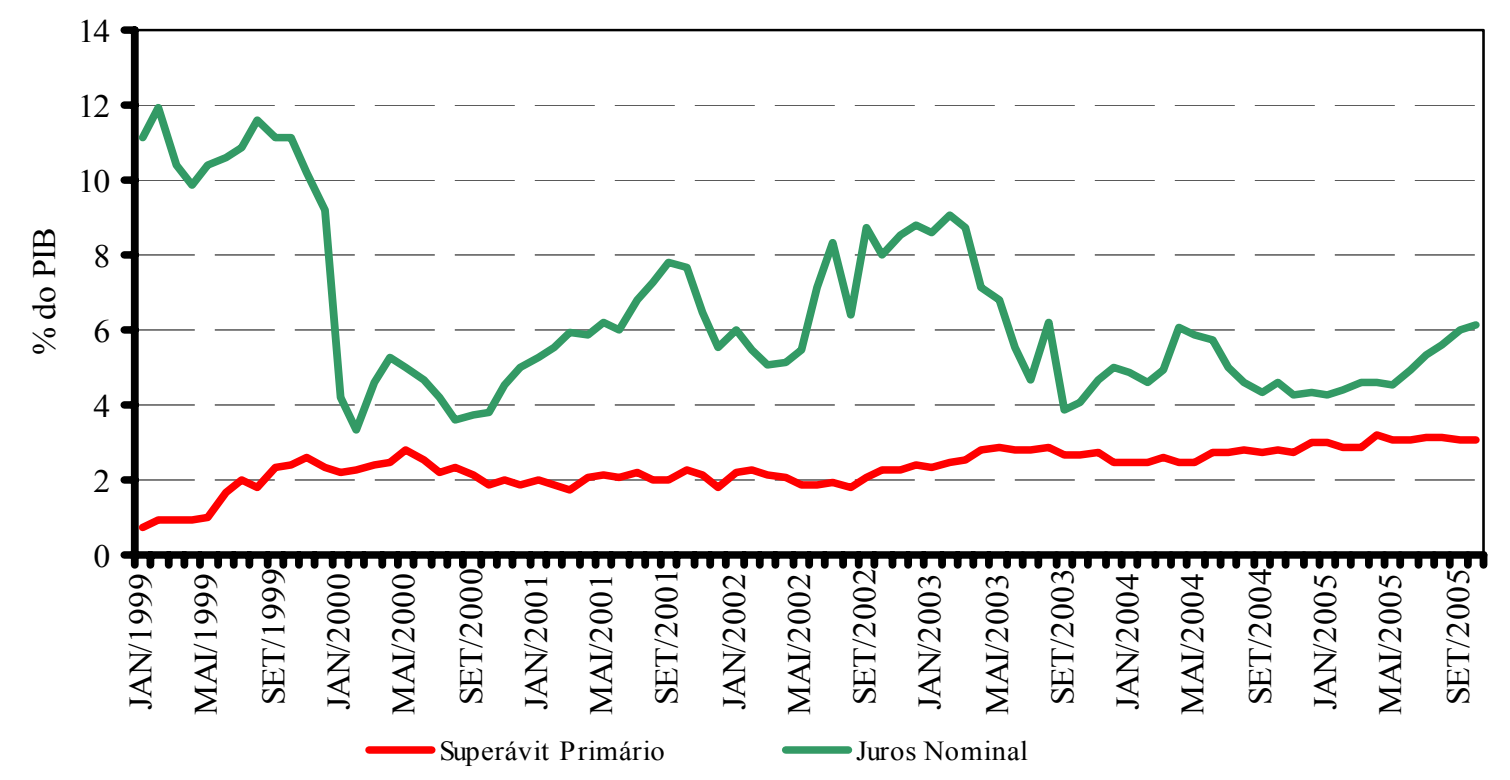

Fonte: Banco Central do Brasil

Em relação aos governos estaduais, a comparação entre o superávit primário e o pagamento de juros (gráfico 3) mostra uma diferença significativa entre ambos, indicando que os governos estaduais não têm conseguido se equilibrar.

Gráfico 3. Evolução do superávit primário e juros nominais - Governos Estaduais
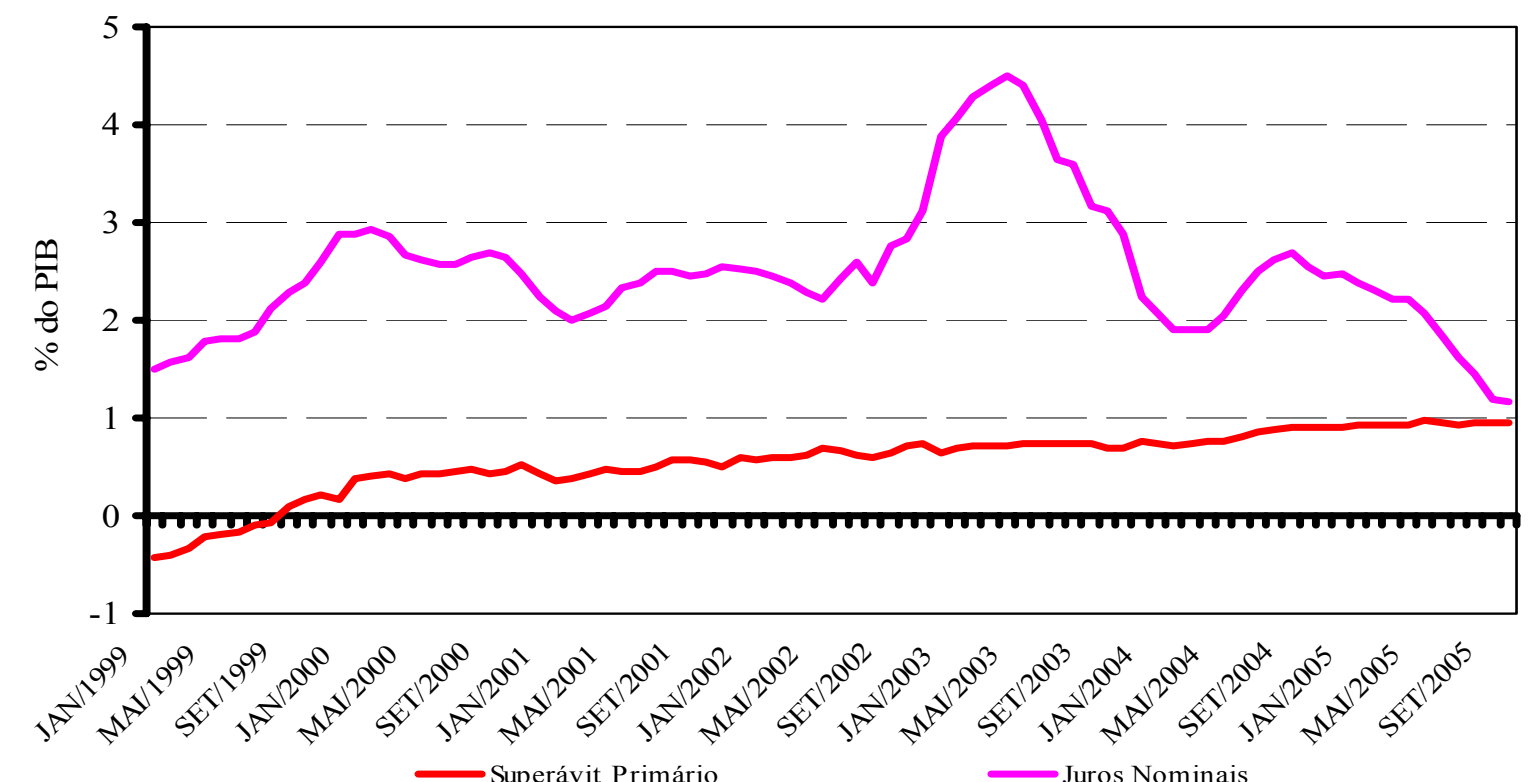

Fonte: Banco Central do Brasil

Contudo, pode-se observar um processo de convergência a partir de 2004. Em 2005, este processo ficou mais evidente e em outubro de 2005 a diferença caiu para 0,21\% do PIB. 
No ano a diferença média ficou em $0,9 \%$ do PIB contra 1,45\% do PIB em 2004 e 2,97\% do PIB em 2003. Apesar da elevação do superávit primário no período, este resultado foi obtido com uma redução significativa do pagamento de juros no período, principalmente com a redução do IGP-DI no ano de 2005 que é o indexador da dívida destes ${ }^{19}$.

\section{Gráfico 4. Evolução do superávit primário e juros nominais - Empresas Estatais}

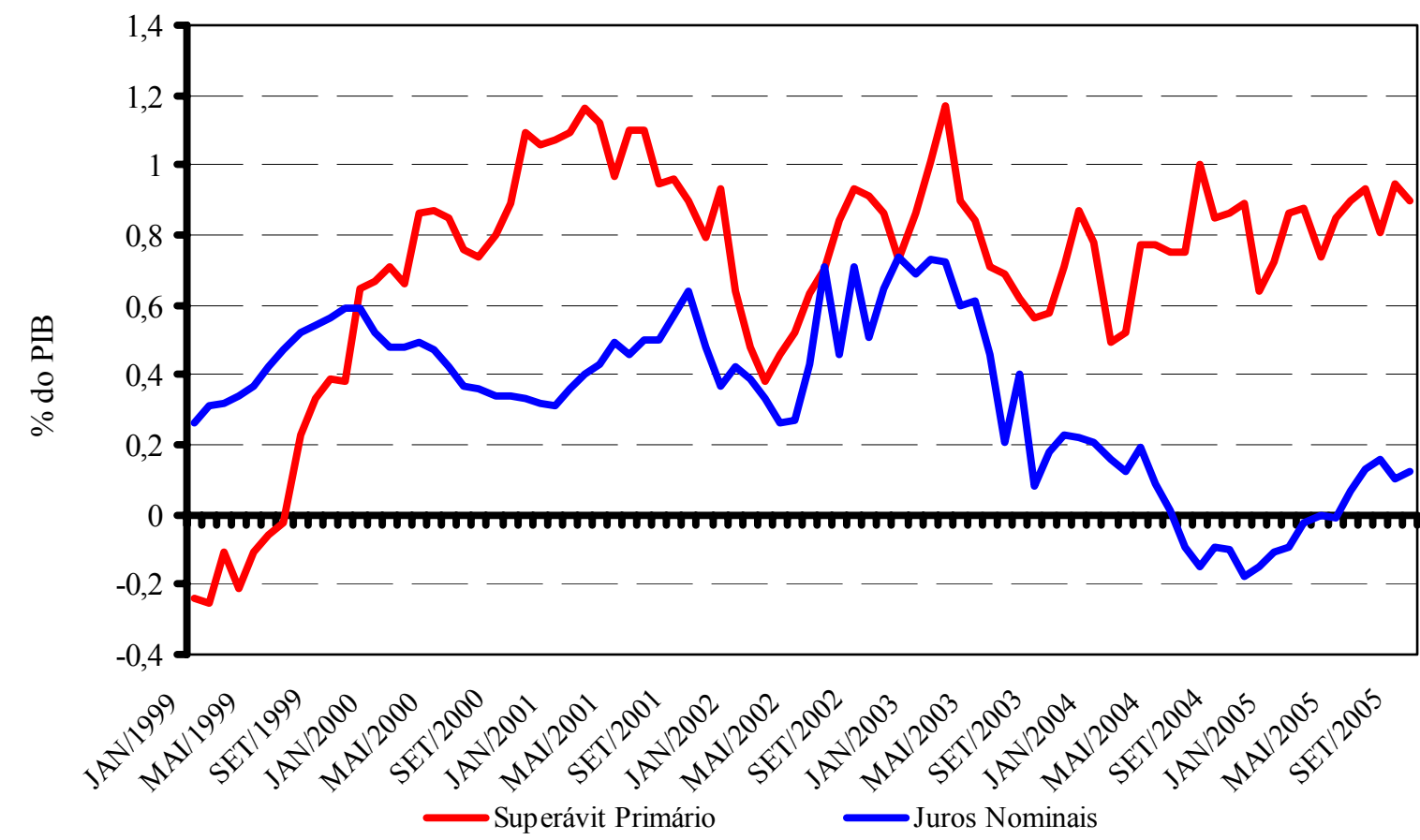

Fonte: Banco Central do Brasil

Quadro diferente dos anteriores pode ser observado quando se analisa as empresas estatais (gráfico 4). A partir de meados de 2000, o superávit primário obtido é maior que os juros pagos. No ano de 2005 a diferença média tem sido de $0,80 \%$ do PIB. Em outras palavras, o esforço fiscal feito pelas empresas estatais tem sido maior que o necessário para seu equilíbrio orçamentário. Este aspecto é importante se for considerado que a maior parte dos investimentos públicos vem desta esfera.

Segundo dados da Câmara dos Deputados, haviam sido liquidados em investimentos públicos R $\$ 5.372$ milhões. Projetando o PIB para 2005 em R $\$ 1.935$ bilhões, atinge-se uma relação investimento/PIB de 0,28\%, três vezes menor do que a economia alcançada pelas empresas estatais (diferença entre o superávit primário e os juros pagos que se aproximou de 0,80\% do Produto Interno Bruto).

\footnotetext{
${ }^{19}$ No caso dos municípios, sua evolução é equivalente à dos estados. Entretanto, o montante é muito pequeno e pode ser desconsiderado sem maiores prejuízos aos argumentos desenvolvidos.
}

82 
Do ponto de vista qualitativo, observa-se que o superávit primário está sendo alcançado com um esforço relativo elevado por parte das empresas estatais. Como estas empresas dão conta de maior parte dos investimentos públicos, estes tem que se reduzir para atingir a meta fiscal. Em outras palavras, a esfera que mais investe é quem está contribuindo mais relativamente para obter o superávit primário.

\section{$O$ custo da política monetária}

O custo que a atual política fiscal tem imposto sobre os investimentos públicos pode ser apresentado de outra forma. A dívida pública brasileira tem um caráter predominantemente pós-fixado e em sua grande parte atrelada à taxa de juros Selic. Assim, uma política monetária restritiva tem efeitos óbvios sobre o montante de juros pagos pelo Governo e, portanto, sobre a sua necessidade de efetuar superávits primários elevados.

Atualmente, a dívida atrelada à taxa Selic representa aproximadamente $27 \%$ do PIB (Banco Central - novembro de 2005). Ou seja, um aumento de 1\% da taxa de juros Selic significaria um custo de $0,27 \%$ do PIB, um valor muito próximo do volume de investimentos do Governo Central em 2005 (0,28\% do PIB).

Portanto, a condução de uma política monetária restritiva tem efeitos significativos sobre a condução da política fiscal tanto em termos quantitativos ao exigir superávits primários elevados quanto em termos qualitativos quando estes acabam por restringir a melhor alocação dos recursos públicos ${ }^{20}$.

A adoção de um superávit primário elevado tem como objetivo tornar viável a política monetária. Entretanto, este é apenas uma das restrições ao aumento do investimento público. $\mathrm{Na}$ verdade, é a menor das restrições, porém em muitas ocasiões tem sido utilizado como justificativa para a sua redução.

\section{Sobre a atual política de gastos públicos}

Mesmo tendo que efetuar um superávit primário elevado para saldar parte dos juros, o governo tem ao seu dispor uma infinidade de combinações entre o montante de gastos e receitas para atingir sua meta de política fiscal. Como exemplo, considere que o governo tem um montante de gastos que avalia ser adequado e que atenda as necessidades da população, mas que tenha que elevar o superávit primário. Então bastaria que elevasse os impostos para

${ }^{20}$ Deve-se ressaltar que as contas aqui apresentadas são aproximações, pois se desconsidera os efeitos que elevações na taxa de juros possuem sobre a inflação (que corresponde a aproximadamente 10\% da dívida total). 
manter viável sua política fiscal. Por outro lado, se considera que a carga tributária é elevada, bastaria fazer uma redução dos seus gastos mantendo-os nos setores que considera prioritário ou que são rígidos e ajustando-nos demais setores. Então a questão crucial passa a ser o que se considera importante ou prioritário.

A Tabela 1 mostra a evolução da participação de cada tipo de gasto em relação ao montante de gastos. Nota-se que três tipos de gastos públicos aumentaram significativamente no período 1999-2004. São eles: (i) benefícios previdenciários, (ii) benefícios sob a Lei Orgânica de Assistência Social (LOAS) e Renda Mensal Vitalícia (RMV) e, (iii) demais gastos assistenciais. Esta elevação se torna evidente a partir de 2002.

A tabela explicita, ainda, a baixa participação dos investimentos públicos (com tendência de queda) e a redução em gastos que se caracterizam por dar maior eficiência ao setor público como pessoal e encargos sociais e outras despesas correntes. Este movimento nos gastos públicos mostra uma mudança na estrutura de gastos. As transferências têm aumentado em detrimento da eficiência e do aumento da produtividade que são possibilitados a partir de maiores investimentos e na política de pessoal.

Tabela 1. Participação dos gastos no total de despesas não-financeiras* (em \%)

\begin{tabular}{l|c|c|c|c|c|c}
\hline \multicolumn{1}{c}{ Tipo de Gasto Não Financeiro } & 1999 & 2000 & 2001 & 2002 & 2003 & 2004 \\
\hline Pessoal e Encargos Sociais & 31,70 & 31,03 & 29,86 & 31,01 & 29,18 & 27,87 \\
Benefícios Previdenciários & 34,95 & 34,43 & 34,06 & 35,54 & 39,35 & 38,33 \\
Benefícios sob a LOAS e RMV & 1,75 & 1,86 & 1,96 & 2,17 & 2,39 & 2,36 \\
Demais Gastos Assistenciais & 0,88 & 0,78 & 0,95 & 1,36 & 1,85 & 2,27 \\
Saúde (Outros Custeios) & 9,05 & 8,68 & 8,43 & 8,55 & 8,33 & 8,27 \\
Investimentos & 4,28 & 5,38 & 6,65 & 4,18 & 2,38 & 3,39 \\
Outras Despesas Correntes & 11,47 & 12,02 & 11,03 & 12,58 & 10,51 & 10,59 \\
Demais Gastos** & 5,92 & 5,82 & 7,06 & 4,60 & 6,01 & 6,92 \\
\hline
\end{tabular}

Fonte: Coordenação de Finanças Públicas (CFP) do IPEA.

*O Total da Despesa Não Financeira foi encontrado excluindo-se juros e encargos da dívida, amortizações, financiamentos e transferências a estados municípios e DF.

**Demais Gastos compreende seguro desemprego e abono, subsídios e subvenções econômicas e inversões financeiras exceto financiamentos.

Esta discussão evidencia um agravante. Apesar do alto custo da política monetária e conseqüentemente a necessidade de realização de um superávit primário elevado, a política de gastos atual colocou em segundo plano a política de investimentos públicos. Ou seja, apesar do superávit primário se constituir em uma restrição para a política fiscal, existe uma segunda restrição que é a prioridade dada pelo Governo Central à questão social. Estes dois fatores têm feito o investimento público ser tão baixo nos últimos anos. 
Portanto, uma redução no superávit primário não garantiria o aumento nos investimentos públicos, ou melhor, alocação dos gastos. Se mantida a atual política de gastos, uma redução no superávit primário significaria, provavelmente, a elevação dos gastos assistenciais do Governo Central tornando a redução dos investimentos públicos mais nítida.

Um terceiro fator que deve ser considerado é o fato de que as empresas estatais é que tem feito o maior esforço fiscal relativo. Como estas são responsáveis pela maior parte dos investimentos do setor público consolidado, tem-se que a forma como o superávit primário vem sendo obtido também é um fator que reprime os investimentos e, portanto, reduz a competitividade da economia brasileira.

\section{Conclusões}

O debate em torno da política fiscal tem focado a questão do tamanho do superávit primário. A necessidade de se manter um superávit primário em patamares elevados se dá em razão do custo da política monetária. Todavia, esta representa apenas uma restrição à condução da política fiscal.

A forma com a qual o superávit primário tem sido obtido gera duas restrições adicionais. A primeira restrição se dá pelo fato das empresas estatais arcarem com a maior parte do custo deste ajuste. A segunda restrição - que não está diretamente associada ao superávit primário - se refere à política de gastos do Governo Central que dá atenção às transferências em detrimento dos gastos associados ao aumento da produtividade como os investimentos públicos (principalmente) e as despesas com pessoal e despesas correntes.

Dessa forma, é de se esperar que uma redução no superávit primário não contribua para o aumento dos investimentos públicos ao passo que sua elevação deverá prejudicar os investimentos ainda mais. A queda dos investimentos públicos se deve muito mais pela prioridade de gastos do Governo que pela restrição imposta pela política monetária. Esta inversão de prioridades é o principal fato fiscal que gera a pífia performance macroeconômica do Brasil. 
